\title{
Trajetos pelos arquivos
}

Taís da Silva Martins*

\begin{abstract}
Resumo: Neste texto, abordamos a questão do arquivo e objetivamos destacá-lo na configuração de uma pesquisa, pois para nós o movimento de configuração e reconfiguração do arquivo bem como o gesto de interpretação do analista são determinantes para o desenvolvimento de um trabalho. Para tanto, buscamos exemplificar nosso trajeto pelos arquivos de nossa dissertação, os quais resultaram na pesquisa que estamos desenvolvendo hoje relacionada a nossa tese.
\end{abstract}

Palavras-chave: Arquivo; Linguística; Disciplinarização.

\section{Introdução}

Em nossa pesquisa atual intitulada Nomeação e designação no processo de disciplinarização de uma ciência, propomos dar continuidade (com novo enfoque) ao trabalho realizado em nossa dissertação intitulada Emergência, movimento e deslocamento da disciplinarização da Análise de Discurso no RS, na qual desenvolvemos uma reflexão inicial sobre o processo de disciplinarização da Análise de Discurso (AD) no RS.

$\mathrm{O}$ arquivo de nossa dissertação foi constituído por dados e fatos referentes a uma história da Linguística nos cursos de Letras no Brasil, na medida em que é no cerne desta disciplina que, no Brasil, a $A D$ se institucionaliza, como também por um conjunto de documentos institucionais, tais como: relatórios anuais, diários de classe, programas, grades de horários e bibliografias da disciplina de Análise de Discurso nos Cursos de PósGraduação em Letras da PUCRS e UFRGS (instituições que primeiro tiveram estes cursos no RS).

A análise dessas textualidades levou-nos a tecer redes de relações acadêmico-intelectuais que dão corporeidade à $\mathrm{AD}$ praticada no RS, pelo trajeto tecido por entre os arquivos que apontaram quais conceitos, quais teóricos, quais sujeitos mobilizam e são mobilizados em uma disciplina que é designada politicamente como $\mathrm{AD}$, bem como é renomeada de outras maneiras e não menos politicamente.

Esse nosso trajeto de pesquisa, para o qual percorremos um caminho que visou a circunscrever uma AD praticada no RS e que foi fundamentado na análise documental de materialidades que institucionalizam uma história ao

\footnotetext{
* Doutoranda em Letras - Estudos Linguísticos, pelo PPGL/UFSM, sob orientação da Prof. ${ }^{\text {a Dr. }}$ Amanda Eloina Scherer. Bolsista Capes. E-mail: taissmartins1@gmail.com
} 
remetermo-las à historicidade que as constitui, indicou-nos a necessidade de compreendermos o jogo político que ocorre no processo de nomeação/renomeação desta disciplina. Isso porque, por meio da leitura deste arquivo, constatamos que os programas que trabalhavam os pressupostos teóricos da $\mathrm{AD}$ apresentavam um movimento constante de nomeações e renomeações.

Cabe salientar que, para nós, as nomeações, renomeações que uma disciplina apresenta fazem parte de um jogo 'político' que vai legitimando conceitos, promovendo certos teóricos e teorias em detrimento de outras. E este jogo se dá dentro das instituições universitárias, lugares aos quais os sujeitos-professores emprestam suas escolhas, seus posicionamentos teóricos. Assim, histórias de vida e história de instituições se confundem. Nesse entremeio, compreendemos que o político delimita. $\mathrm{O}$ político circunscreve, emoldura uma teoria, dita um caminho, divide o dizer e ele não está dado, ele precisa ser pensado à luz da teoria que o articula.

\section{Do arquivo...}

Inserimo-nos em uma perspectiva teórica que pode ser entendida ao modo de uma articulação entre AD e HIL, tal como formula Nunes ao afirmar que "há uma produtividade específica quando a $\mathrm{AD}$ se posiciona no entremeio com a HIL" (2007a, p.03). Nessa perspectiva teórico-analítica, o analista lança sobre o corpus um olhar diferenciado do pesquisador que faz a historiografia de uma disciplina, na medida em que não (só) 'conta' uma história, mas se insere em 'uma' história para movimentá-la, para indagá-la, para pôr em diálogo os arquivos que a constituem, para trazer outros à tona, para instaurar uma 'historicidade', tendo em vista que a questão que se coloca não é a de linearidade temporal, e sim a temporalidade que constitui o texto (cf. Orlandi, 1996).

Esta articulação permite que, ao tratarmos de temas abordados pela HIL, como conceitos, teorias, autores, instituições, periodização, trabalhemos de maneira específica, através de uma abordagem discursiva. Guimarães (2002, p.13), ao referir-se ao que seria uma história das ideias, postula:

Trata-se para mim, de poder acompanhar como certos conceitos, certas noções, certas categorias se constituíram e como ao permanecerem mudaram, ou ganharam contornos específicos. Ou seja, em que momento encontramos acontecimentos pelos quais um conceito se constitui, permanece ou se torna outro.

A importância de conhecermos este processo de nomeação/designação da disciplina $\mathrm{AD}$ nos programas de Pós-Graduação do RS se dá também porque entendemos que é a partir destas (re)nomeações que 
ocorre a disciplinarização da $\mathrm{AD}$ e que, consequentemente, este campo do saber ganha espaço no cenário acadêmico gaúcho. É a partir desta nomeação que trabalhos de pesquisa que utilizam o pressuposto teórico da $\mathrm{AD}$ de linha francesa começam a ser divulgados e a circular, é como se a nomeação instaurasse a disciplinarização.

Outro aspecto que consideraremos é que, no Brasil, a história da constituição da disciplina de $\mathrm{AD}$ não pode estar desvinculada da história dos Programas de Pós-Graduação em Letras e, menos ainda, da história de vida acadêmica dos sujeitos-professores. Nesse sentido, precisamos também conhecer a formação dos sujeitos-professores que estão no cerne da constituição desta disciplina em questão nas instituições.

Acreditamos que a ausência de uma reflexão sobre a história produz demarcações territoriais que multiplicam os rótulos a partir de deslocamentos, inversões, apagamentos do percurso de construção dos conceitos e de seus formuladores. Nosso objetivo principal, com este novo trabalho, é o de assinalar como os profissionais que, no Estado do Rio Grande do Sul, primeiro trabalharam com a disciplina $\mathrm{AD}$, designaram-na e configuraram-na e, com isso, tomaram parte no processo de disciplinarização deste campo do saber em nosso Estado.

Baseando-nos em Orlandi (2001, p. 50), entendemos que "uma metodologia dentro desta perspectiva (HIL) trata de seu objeto lingüístico pela construção de sua história". Em relação à História das Ideias Linguísticas, Orlandi (2002, p.12) afirma ainda que

[...] podemos classificar em três categorias as iniciativas de contar essa história, são elas: a) as dos que visam constituir uma base documental para pesquisa empírica; b) as que estão em continuidade com uma prática de conhecimento da qual derivam; c) as que têm um papel fundador, que se voltam para o passado com a finalidade de legitimar uma prática científica contemporânea.

Nessa história, procuramos conhecer os processos que permeiam a nomeação e designação da disciplina $\mathrm{AD}$ nas instituições pesquisadas. Realizamos nosso trabalho em consonância com Lagazzi-Rodrigues (2007) quando a autora coloca que "A História das Idéias Lingüísticas é uma história sempre tensa, marcada por injunções, possibilidades e apagamentos”. E são a essas injunções, possibilidades e apagamentos que procuramos dar visibilidade neste trabalho.

Para recuperarmos a história constituição da disciplina de AD dentro das instituições por nós pesquisadas e entendermos a questão política envolvida no movimento de nomeação/renomeação da mesma, adotamos a perspectiva de arquivo proposta por Pêcheux (1997) como 'campo de documentos pertinentes e disponíveis sobre uma questão’. Como já colocamos 
anteriormente, destacamos que compreendemos o arquivo de nossa pesquisa como uma "materialidade discursiva que traz as marcas da constituição dos sentidos" (Nunes, 2007, p.374). Orlandi (1996, p.54.) afirma que a "AD é um marco na HIL, em uma mudança que toca essa distinção entre história e historicidade". Para Nunes (2007), o termo historicidade funciona para diferenciar a posição do analista de discurso em relação à do historiador.

Para o analista, a história é constitutiva de sentidos e não mais como pano de fundo. Assim, para nós, conforme o autor (Ibid.), o material de arquivo está sujeito à interpretação e não vem a ser um espaço de comprovação. Consideramos ainda a afirmação de Guilhaumou e Maldidier de que

[...] todo arquivo, principalmente manuscrito, é identificado pela presença de uma data, de um nome próprio, de uma chancela institucional etc., ou ainda pelo lugar que ele ocupa em uma série. Essa identificação puramente institucional é para nós insuficiente: ela diz pouco sobre o funcionamento do arquivo (1997, p. 164).

O analista precisa construir dispositivos de análise de arquivo, em que se possa observar os processos de constituição dos sentidos e se consiga ultrapassar esta relação imediata com as instituições (Nunes, 2007a). Em nosso entender, a construção do arquivo em si é tão importante quanto a construção dos dispositivos de análise de um arquivo, pois é a partir da constituição do arquivo que a pesquisa se 'corporifica'. Difícil é o trabalho do pesquisador ao construir um arquivo, pois cabe a ele levantar o maior número de fontes possíveis para a sua análise, o que faz com que ele produza uma busca incessante de fontes que possam contribuir para o desenvolvimento de seu trabalho. Nas palavras de Fávero (2004), esta é uma empreitada perigosa no que diz respeito à dificuldade do acesso à documentação, à dispersão deste e, especialmente, ao estudo da documentação.

Percebemos que, para esse trabalho, precisamos ampliar o arquivo de nossa pesquisa. Mesmo considerando que o arquivo de nossa dissertação já possua muitos dados ( 8 bibliografias, 10 programas, 20 currículos, 23 diários de classe, 16 grades de horário), pretendemos agregar a ele novos materiais, como, por exemplo, entrevistas com os sujeitos-professores que ministraram e os que ministram a disciplina AD nos Cursos de Pós-Graduação no RS, publicações realizadas por estes professores, entre outros. Após este acréscimo em nosso arquivo é que iremos definir corpus de nossa pesquisa.

Este é um movimento de (re)configuração de arquivo que certamente ocorrerá porque entendemos que "a leitura do arquivo deve ser antes um ato político no interior de um espaço de leitura polêmico, onde se produzem e se reproduzem discursos" (Silveira, 2000, p. 122). Para nós, são os gestos de leitura no/sobre o arquivo que permitem a configuração do corpus de uma 
pesquisa, pois, conforme Orlandi (1999), a constituição do corpus requer recortes que são da ordem de gestos de leitura. Para Pêcheux (1990), recortar requer ler, descrever e interpretar.

O arquivo de nossa pesquisa é formado por uma heterogeneidade de materialidades, pois entendemos que em um trabalho perpassado por questões da $\mathrm{AD}$ e da HIL é de fundamental importância a construção de um arquivo que recubra vários aspectos das questões de pesquisa e que possa auxiliar na (re)configuração do corpus quantas vezes for necessário durante a elaboração do estudo.

Ressaltamos, no entanto, que não pretendermos, em nossa análise, dar conta desta multiplicidade de dispositivos textuais disponíveis. Entendemos que esta multiplicidade de materialidades é necessária apenas para que possamos recorrer a estes dispositivos sempre que necessário para compreendermos as questões abordadas em nossa pesquisa, pois consideramos que

[...] o corpus não é mais um conjunto estanque de textos, é um conjunto sem fronteiras no qual o interdiscurso, exterior, irrompe no intradiscurso. Sua construção supõe renunciar ao sonho de uma interpretação fechada e garantida por uma leitura explicitada em proveito de uma leitura-escrita e de uma "política de interpretação" que se basearia na avaliação das "forças de interpretação em uma conjuntura” (MAZIÉRE, 2007, p. 61).

Compreendemos que, o corpus constitui uma 'rede de memórias' (Mazière, 2007), nada estática, onde a todo o momento, na medida em que se faz necessário, ao decorrer das análises, nos permite recorrer aos arquivos e (re)configurar seu estado.

Nosso gesto de interpretação é norteado pela questão teórico-analítica sobre designação e nomeação. Interessamo-nos pela constituição da cena política imbricada no movimento de nomeação/renomeação e designação da disciplina AD nos Cursos de Pós-Graduação do RS, pois, como dissemos anteriormente, acreditamos que este movimento está no cerne da instauração de um campo do saber como disciplina em uma instituição.

\section{Considerações finais}

Tratamos a questão da disciplinarização sob o enfoque do jogo político institucional que permite (ou não) que um campo do saber seja institucionalizado e que determina o que pode ou não ser dito a respeito de determinada teoria, em nosso caso, a Análise de Discurso de linha francesa. E, para tanto, recorremos a arquivos institucionais e pessoais a fim de 
circunscrevermos 'redes de memória' de modo a constituírem um panorama histórico acerca da disciplina.

Uma reflexão que propomos no momento diz respeito ao que Orlandi (2005) postula em relação ao esquecimento como um dos modos de o político se marcar em relação à memória, ideologicamente. Assim sendo, questionamos quais os lugares esquecidos - já que falar é esquecer -, quais não foram salientados no momento da configuração da AD nos Cursos de PósGraduação do RS por terem sido silenciados pelo jogo do político que se configurou durante este processo de disciplinarização.

\section{Referências}

GUILHAUMOU, J.; MALDIDIER, D. Efeitos do arquivo. A análise do discurso no lado da história. Traduzido por S. Lagazzi; J. H. Nunes. In: ORLANDI, E. Puccinelli (org.). Gestos de leitura: da história no discurso. Campinas: Unicamp, 1997. p. 163183.

GUIMARÃES, E. Semântica do acontecimento: um estudo enunciativo da designação. Campinas: Pontes, 2002.

LAGAZZI-RODRIGUES, S. O político na lingüística: Processos de legitimação e institucionalização. In: ORLANDI, E. P. (org) Política lingüística no Brasil. Campinas: Pontes, 2007.

MAZIÉRE, F. Análise do Discurso: história e práticas. Traduzido por M. Marcolino. São Paulo: Parábola, 2007.

NUNES, J. H. Leitura de arquivo: historicidade e compreensão. Texto apresentado no II SEAD, Porto Alegre, UFRGS, 2005. Disponível em: http://www.discurso.ufrgs.br/sead2/doc/interpretacao/Jose_horta.pdf. Acesso em: 15 jul. 2007.

. Uma articulação da análise de discurso com a história das idéias Lingüísticas. Texto apresentado no VIII Seminário Corpus - História das Idéias Lingüísticas. Santa Maria: UFSM/ Laboratório Corpus. set.2007a. [texto inédito]

ORLANDI, Eni P. Interpretação: Autoria, leitura e efeitos do trabalho simbólico. Petrópolis: Vozes, 1996.

. Análise de Discurso: Princípios e Procedimentos. Campinas: Pontes, 1999.

. História das Idéias Lingüísticas: construção do saber metalingüístico e constituição da língua nacional. Campinas: Pontes; Cáceres: UNEMAT, 2001.

. Língua e conhecimento lingüístico: para uma história das idéias no Brasil. São Paulo: Cortez, 2002. 2005.

. Discurso e Texto: formulação e circulação dos sentidos. Campinas: Pontes,

PÊCHEUX, M. O discurso: estrutura ou acontecimento. Traduzido por E. P. Orlandi. Campinas: Pontes, 1990. 
. Ler o Arquivo Hoje. Traduzido por M.G.L.M. do Amaral. In: ORLANDI, Eni P. (org.) [et.al.]. Gestos de leitura. Da História no Discurso. 2.ed. Campinas: Unicamp, 1997.

SILVEIRA, V. P. Por um acesso fecundo ao arquivo. Revista Letras. Programa de Pós-Graduação em Letras. UFSM. n 21, Jul.-dez, 2000. p. 121-127. 